\title{
The Iflaviruses Sacbrood virus and Deformed wing virus evoke different transcriptional responses in the honeybee which may facilitate their horizontal or vertical transmission
}

Eugene V Ryabov, Jessica M Fannon, Jonathan D Moore, Graham R Wood, David J Evans

Sacbrood virus (SBV) and Deformed wing virus (DWV) are evolutionarily related positivestrand RNA viruses, members of the Iflavirus group. They both infect the honeybee Apis mellifera but have strikingly different levels of virulence when transmitted orally. Honeybee larvae orally infected with SBV usually accumulate high levels of the virus, which halts larval development and causes insect death. In contrast, oral DWV infection at the larval stage usually causes asymptomatic infection with low levels of the virus, although high doses of ingested DWV could lead to DWV replicating to high levels. We investigated effects of DWV and SBV infection on the transcriptome of honeybee larvae and pupae using global RNA-Seq and real-time PCR analysis. This showed that high levels of SBV replication resulted in down-regulation of the genes involved in cuticle and muscle development, together with changes in expression of putative immune-related genes. In particular, honeybee larvae with high levels of SBV replication, with and without high levels of DWV replication, showed concerted up-regulated expression of antimicrobial peptides (AMPs), and down-regulated expression of the prophenoloxidase activating enzyme (PPAE) together with up-regulation of the expression of a putative serpin, which could lead to the suppression of the melanisation pathway. The effects of high SBV levels on expression of these immune genes were unlikely to be a consequence of SBV-induced developmental changes, because similar effects were observed in honeybee pupae infected by injection. In the orally infected larvae with high levels of DWV replication alone we observed no changes of AMPs or of gene expression in the melanisation pathway. In the injected pupae, high levels of DWV alone did not alter expression of the tested melanisation pathway genes, but resulted in up-regulation of the AMPs, which could be attributed to the effect of DWV on the regulation of AMP expression in response to wounding. We propose that the difference in expression of the honeybee immune genes induced by SBV and DWV may be an evolutionary adaptation to the different predominant transmission routes used by these viruses. 
1 Title:

2 The Iflaviruses Sacbrood and Deformed wing virus evoke different transcriptional 3 responses in the honeybee which may facilitate their horizontal or vertical transmission

6 Authors:

7 Eugene V. Ryabov ${ }^{*}$, Jessica M. Fannon', Jonathan D. Moore², Graham R. Wood², David J. 8 Evans ${ }^{1,3}$

${ }^{1}$ School of Life Sciences, University of Warwick, Coventry, CV4 7AL UK

${ }^{2}$ Warwick Systems Biology Centre, University of Warwick, Coventry, CV4 7AL UK

3 Present address: Biomedical Sciences Research Complex, North Haugh, University of St.

\section{*Corresponding author:}

Eugene V. Ryabov ( eugene.ryabov@warwick.ac.uk )

Subjects: Entomology, Virology, Microbiology, Infectious diseases, Apis mellifera, RNA-Seq Keywords: Antimicrobial peptide, Apis mellifera, deformed wing virus, DWV, honeybee, iflavirus, innate immunity, RNA virus, RNA-Seq, sacbrood virus, SBV, transcriptome, insect

21 imunity 


\section{Introduction}

The Western honeybee, Apis mellifera, is the most important managed insect pollinator

worldwide. In recent decades a global decline in the number of honeybee colonies was reported, threatening security of the global food supply (Vanbergen et al., 2013), with pathogens - in particular viruses - contributing significantly to these declines. These viral pathogens are predominantly single-stranded, positive sense RNA viruses of the families Dicistroviridae and Iflaviridae, and may exhibit differing virulence levels, causing infections ranging from asymptomatic to acute and resulting in rapid insect death (McMenamin \& Genersch, 2015). It is also apparent that some viruses exhibit strain differences in virulence. For example, the most widespread honeybee virus, Deformed wing virus (DWV) (de Miranda \& Genersch, 2010; Lanzi et al., 2006) and the very closely related variants Varroa destructor virus-1 (Ongus et al., 2004) and Kakugo virus (Fujiyuki et al., 2004), usually cause asymptomatic infections with low levels of the virus when transmitted vertically or orally. In contrast, DWV transmission by the ectoparasitic mite Varroa destructor - by direct injection to the honeybee haemolymph - results in the selection of highly pathogenic strains of DWV with significantly reduced genetic diversity

41 (Martin et al., 2012; Ryabov et al., 2014) which accumulate to very high levels in infected pupae and cause characteristic symptoms, including deformed wings and shortened abdomen. The doses of DWV, including its virulent strains, which are delivered orally to larvae during brood rearing cause only asymptomatic infections and accumulate to low levels, making it possible for infected honeybees to survive to adulthood and transmit the virus horizontally or vertically

46 (Ryabov et al., 2014; Yue \& Genersch, 2005). In contrast to DWV, Sacbrood virus, (SBV, a related member of the Iflaviridae) a predominant viral pathogen in the Asian honeybee Apis

cerana, accumulates to high levels and causes acute infections in orally inoculated honeybee 
49 larvae (Ai, Yan \& Han, 2012; Bailey, Gibbs \& Woods, 1964; Ghosh et al., 1999). SBV infection

50 has a much more pronounced impact on honeybee development than DWV; honeybee larvae

51 with high levels of the virus have a gondola-shaped sac-like appearance with tough leathery skin

52 and die before pupation. It is likely that SBV is transmitted from the larvae killed by SBV to in-

53 hive worker honeybees, which subsequently transmit the virus to young larvae (Bailey, 1969).

In this study, we analyzed global honeybee transcriptional responses to both DWV and

SBV using RNA-Seq. We further analyzed the impact of DWV and SBV on the expression of several immune related genes of the honeybee by real-time PCR (qRT-PCR). We found that different sets of genes were differentially expressed (DE) in honeybee larvae with high levels of either DWV alone or SBV and DWV combined, and that high levels of SBV infection had a more significant impact on global gene expression in the honeybee compared to high levels of DWV, in particular on the expression of immune-related genes. We found, in both larval feeding and pupal injection experiments, that high levels of SBV were associated with up-regulation of the expression of antimicrobial peptide (AMP) genes and changes in expression of the genes involved in regulation of melanisation, which may suppress this function. These differential effects of DWV and SBV on expression of AMP and melanisation pathway genes may be an adaptation of these viruses to facilitate their vertical and horizontal routes of transmission respectively.

Materials \& Methods

\section{Honeybee rearing, virus preparations and inoculation}

Colonies of healthy Western honeybees (Apis mellifera) with low managed levels of Varroa destructor infestation were maintained in Warwickshire, UK, and used as a source of 
72 larvae and pupae. DWV virus preparation was isolated from honeybee pupae sourced from a

73 colony with high Varroa infestation levels. Virus preparations containing both SBV and DWV

74 (SBV+DWV) were purified from larvae and pupae of the Varroa-infested colonies where some

75 larvae showed typical SBV-induced symptoms. No other known honeybee viruses were detected

76 in the prepared virus stocks. Virus isolation was carried out as described previously (Moore et

77 al., 2011) and the virus preparations were stored at $-80^{\circ} \mathrm{C}$ prior to use. For inactivation, the virus

78 preparations were irradiated by UV light (Simonet \& Gantzer, 2006).

Artificial rearing of the honeybee larvae was carried out essentially as described 80 previously (Aronstein \& Saldivar, 2005; Vandenberg \& Shimanuki, 1987). For oral inoculation 81 newly hatched honeybee worker larvae were transferred to an artificial honeybee larval diet and 82 maintained at $+33^{\circ} \mathrm{C}$. After $12 \mathrm{hr}$ the larvae were orally inoculated with a single dose of the virus 83 preparation containing SBV and DWV. Approximately $10^{10} \mathrm{SBV}$ and $10^{10} \mathrm{DWV}$ virus particles 84 (SBV+DWV) were added to $50 \mu \mathrm{l}$ of the honeybee rearing diet per bee, which was consumed within $12 \mathrm{hr}$. No virus was added to the subsequent portions of the larval food. The controls in the feeding experiment included virus-free phosphate-buffered saline (PBS), and the UVinactivated $\mathrm{SBV}+\mathrm{DWV}$ virus preparation (UV-inactivated virus, $\mathrm{SBV}+\mathrm{DWV})$. The larvae were maintained for an additional 9 days up to the late fourth instar stage. Whole-body RNA samples were extracted from individual insects at 4 days post inoculation (dpi) or 9 dpi.

For the honeybee pupa infection, worker pupae sourced at the white eye stage $\left(12^{\text {th }}\right.$ to $9113^{\text {th }}$ days of development) received injections into the haemolymph using a syringe with a 0.3

$92 \mathrm{~mm}$ outer diameter needle (Ryabov et al., 2014) either with $10 \mu \mathrm{l}$ of phosphate-buffered saline 93 (PBS), or with DWV preparations $\left(10^{6} \mathrm{DWV}\right.$ virus particles in PBS), or with the mixture of SBV 94 and DWV $\left(10^{6} \mathrm{SBV}\right.$ and $10^{6} \mathrm{DWV}$ virus particles in PBS). The pupae were reared at $+33^{\circ} \mathrm{C}$ as 
95 previously described (Ryabov et al., 2014). Whole-body RNA samples were extracted from

96 individual pupae at 2 dpi or 5 dpi.

98 Gene expression analysis

99 Total RNA was extracted from individual pupae with Tri-reagent (Trizol) (Ambion)

100 according to the manufacturer's instructions. The extracted column-purified total RNA from

101 individual honeybees was used for high-throughput sequencing of the mRNA populations by

102 RNA-Seq. The experiment and the reads were deposited into the European Nucleotide Archive

103 under accession number PRJEB6511 (http://www.ebi.ac.uk/ena/data/view/PRJEB6511).

104 Quantification of viral RNA and the honeybee transcripts were carried out by quantitative

105 reverse transcription PCR (qRT-PCR) as described previously (Ryabov et al., 2014). In brief, the

106 RNA samples were treated with RNA-free DNAse1 (New England BioLabs), purified using

107 RNAeasy plant mini kit (Qiagen) and used for cDNA synthesis with random hexanucleotide

108 primers. qRT-PCR reactions were performed using SYBR Green kit (Ambion) with the primers

109 to viral RNA and to the honeybee transcripts (Table S1). Tukey's Honest Significant Difference

110 test (Tukey's HSD) was used to determine significantly different virus and gene expression levels

111 (Tukey, 1949).

112

\section{Bioinformatics}

114 The RNA-Seq reads were aligned using Bowtie2 (Langmead et al., 2009) (with the least

115 stringent alignment settings to allow detection of the sequence variants, "--very-sensitive"

116 option) to the latest honeybee transcriptome annotation (OGS3; containing 16041 putative

117 transcripts), as well as to a set of sequences of the known fungal and viral pathogens of the 
118 honeybees used previously (Bull et al., 2012; Ryabov et al., 2014). We used samtools idxstats to

119 produce a summary of the number of reads aligning to the honeybee transcriptome and the DWV

120 and SBV reference sequences (GenBank accession numbers NC_004830 and AF092924

121 respectively). The Next Generation Sequencing (NGS) gene expression profiles were used to

122 identify differentially expressed (DE) genes using DESeq (Anders \& Huber, 2010) and edgeR

123 (Robinson, McCarthy \& Smyth, 2010), with adjusted $p$-values and a false discovery rate (FDR)

124 below 0.05 . Drosophila homologues of the honeybee genes were identified previously (Ryabov

125 et al., 2014) and those DE in the contrasts were used for Gene Ontology (GO) analysis

126 (Ashburner et al., 2000) using AmiGO (Carbon et al., 2009).

128 Results

129 Oral infection of honeybee larvae with DWV and SBV

130 Artificially reared honeybee worker larvae were orally inoculated with virus preparations

131 containing SBV and DWV ("SBV+DWV") and controls included UV-inactivated

132 "SBV+DWV" virus preparation and PBS (Fig. 1A). The doses of both DWV and SBV, $10^{10}$

133 genome equivalents, were sufficient to allow replication of the viruses to high levels when

134 ingested at the larval stage (Ryabov and Evans, unpublished). Notably, this DWV dosage was

135100 times higher than a dose used in oral infection of the adult bees which did not result in

136 establishing high levels of DWV infection (Moeckel, Gisder, \& Genersch, 2011). Quantification

137 of SBV and DWV in the experimental insects assayed at 9 dpi showed that individuals of both

138 control groups had low levels of both DWV and SBV (Ct values 31 to 22, and 32 to 24

139 respectively), while among the virus-fed insects there were individuals with high levels of either

140 DWV or SBV, as well as those with high levels of both viruses (Ct values 8 to 14, and 9 to 15). 
141 For comprehensive characterization of honeybee gene expression in response to high

142 levels of DWV and SBV, we used an RNA-Seq approach. The analysis was carried out using

143 whole-body RNA extracted from individual honeybee pupae sampled at 9 dpi. Controls included

144 pupae with low levels of DWV and SBV (samples 1 and 2) for comparison with the three virus-

145 infected samples; one of these (sample 3) had high level of DWV and low level of SBV, and two

146 samples had high levels of both SBV and DWV (samples 4 and 5) (Fig. 1A, Table 1).

147 Approximately 10 million $101 \mathrm{nt}$ reads were produced for each library (Table 1) and were

148 aligned to the latest honeybee transcriptome annotation (OGS3) and to the sequences of known

149 fungal and viral pathogens of the honeybees used previously (Bull et al., 2012; Ryabov et al.,

150 2014). Apart from DWV-like viruses and SBV (GenBank accession numbers NC_004830 and

151 AF092924 respectively) no other pathogens were detected. We observed a dramatic increase of

152 DWV and SBV coverage, normalized to host actin mRNA coverage (GB44311), in infected

153 honeybees compared to controls (Table 1). For example, there was an $\sim 1000$-fold increase in

154 DWV reads in virus-infected pupae (samples 3, 4 and 5) compared to controls (samples 1 and 2),

155 from 0.05 to $\sim 50$ in concordance with previously reported actin-normalized levels of DWV in

156 pupae with low (0.1 genomes/actin mRNA) and high (10-100 genomes/actin mRNA) levels of

157 DWV by qRT-PCR (Moore et al., 2011; Ryabov et al., 2014). SBV levels showed over 1000-

158 fold increase in samples 4 and 5 compared to the control samples (1 and 2) and sample 3; the

159 ratios of SBV to actin read coverage increased from $0.04-0.20$ to $378-573$ (Table 1). The

160 observed increase of the SBV load was similar to previously reported differences between SBV

161 levels in asymptomatic honeybee larvae with low SBV levels and the symptomatic larvae with

162 high SBV (Blanchard et al., 2014). 
164 RNA-Seq analysis reveals that high levels of DWV, and SBV with DWV co-infection, evoke

\section{5 different transcriptional responses in orally infected honeybee larvae}

166 We stratified the RNA-Seq samples according to the levels of DWV and SBV (high and low)

167 into three groups, "Control" (samples 1 and 2), "DWV" (sample 3), and "SBV+DWV" (samples

1684 and 5) and, by using both DESeq (Anders \& Huber, 2010) and edgeR (Robinson, McCarthy \&

169 Smyth, 2010), identified differentially expressed (DE) genes in five contrasts (Fig. 2, Table S2)

170 to assess the effect of virus infections on the host gene expression. Potential functional

171 consequences of DE were inferred following overrepresented Gene Ontology (GO) analysis

172 (Ashburner et al., 2000; Table S3).

173 The highest numbers of DE genes were identified in the contrasts involving the 174 "SBV+DWV" group. Of these, contrast 4 (high SBV+DWV vs control) had 1638 DE genes, 175 which included almost all (1076 of 1088) of those identified as DE in Contrast 2 (high 176 SBV+DWV vs. control and high DWV alone). High commonality, 697 of 824 genes, was also 177 observed between the DE genes in Contrast 5 and Contrast 4 (high SBV+DWV vs. high DWV 178 alone and high SBV+DWV vs. control respectively (Fig. 2). The direction of gene expression 179 change was the same (e.g. genes up-regulated in Contrast 4 were also up-regulated in Contrast 180 5).

The number of DE genes in Contrast 3 (transcriptome changes associated with high

182 DWV levels alone) was lower than those observed in Contrasts 2, 4 and 5, all of which involved 183 the SBV+DWV group (Fig. 2). A very low number of genes $(n=4)$ was identified in Contrast 1

184 (common response to high levels of DWV alone and high levels of SBV+DWV), and the low 185 commonality between Contrasts 3 and $4(n=9)$ strongly suggested that transcriptional responses 186 to high levels of DWV and SBV+DWV were different (Fig. 2). Indeed, GO analysis (Table 2, 
187 Table S3) showed that different overrepresented GO terms were associated with the DE genes in

188 Contrast 3 (high DWV levels) compared with the genes in Contrasts 2, 4, and 5 (high levels of

189 SBV and DWV), providing further evidence that high level replication of SBV or DWV affected

190 different biological processes in the honeybee. When compared with the low virus level control,

191 the insects with high DWV levels (Contrast 3) showed up-regulation of the genes involved in

192 translation, metabolic processes, and ATP metabolism (Table 2, Table S3). Changes in

193 honeybee gene expression associated with high levels of SBV+DWV were more pronounced

194 when compared to those associated with high DWV levels alone. The down-regulated DE genes

195 associated with increased levels of SBV (Contrasts 2, 4, and 5) were involved in cuticle and

196 muscle development (Table 2, Table S3), consistent with the reported phenotypic effects of SBV

197 infection, which include halted development and abnormal cuticle (Bailey, Gibbs \& Woods,

198 1964). Surprisingly, despite very low commonality between Contrasts 3 and 4, a considerable

199 proportion of DE genes in Contrast 3 (68 of 223) were also DE in Contrast 5 (Fig. 2). However,

200 the vast majority of these (67/68) exhibited virus-dependent DE in opposing directions, i.e. genes

201 up-regulated in response to high levels of DWV alone were down-regulated in response to high

202 levels of SBV, even in the presence of high levels of DWV (Table S4). The over-represented GO

203 terms associated with these genes indicated that high levels of DWV induced increased

204 expression of the genes involved in ATP metabolism, whereas high levels of SBV had the

205 opposite effect on the expression of these genes, overriding the effect of DWV on their

206 expression (Table 2, Table S4). In respect to the genes up-regulated in response to high levels of

207 SBV we were particularly intrigued with the over-representation of GO terms associated with

208 immune response, e.g. "Immune system process", "Defense response” (Table 2, Table S3). 


\section{Differing effects of DWV and SBV on the expression of immune-related genes}

212 Of 381 putative immune-related genes of the honeybee identified in previous studies

213 (Evans et al., 2006; Ryabov et al., 2014), 98 were DE among the contrasts of the RNA-Seq

214 experiment (Fig. 2, Table S5) with 74 of these genes in contrast 2 (high SBV+DWV vs. high

215 DWV alone and control), 94 of these DE in contrast 4 (high SBV+DWV vs. control), 57 of these

216 genes in contrast 5 (high SBV+DWV vs. high DWV alone) (Fig. 2, Table S5). Strikingly, there

217 were 54 DE immune-related genes shared in contrasts 2, 4 and 5, converging at the high

218 SBV+DWV group (Fig. 2, Table S3). In particular, we observed dramatic up-regulation (30- to

219 1000-fold) of six antimicrobial peptide (AMP) genes (Table 3, Table S5). Expression of AMPs

220 in insects is controlled by the Toll and the Imd signaling pathways (De Gregorio et al., 2002).

221 Notably, in honeybees abaecin (GB47318) and hymenoptaecin (GB51223) are controlled by the

222 Imd pathway (Schluns \& Crozier, 2007), while others are likely controlled by the Toll pathway

223 (Evans et al., 2006), implying that both pathways are activated in pupae with high SBV levels. In

224 addition, high SBV levels also influenced expression of the Toll pathway genes, including up-

225 regulation of PGRP-SA (GB51741), persephone (GB55007), spatzle (GB52631) and one of the

226 Toll receptors (GB50418), and down-regulation of two other Toll receptors (GB40699 and

227 GB43456) (Table 3). We also observed changes in expression of the genes involved in regulation

228 of the melanisation pathway e.g. the simultaneous down-regulation of the prophenoloxidase

229 activating enzyme (PPAE, GB50013), the only honeybee enzyme which proteolytically cleaves

230 prophenoloxidase (Soderhall \& Cerenius, 1998) and up-regulation of two putative serpins, the

231 negative regulators of the proteolytic event in the melanisation and signaling pathways (NEC- 
232 like proteins, GB48820 and GB54611) (Table 3). We propose that these changes in gene 233 expression may result in suppression of the melanisation pathway.

234 To further explore the possible connection between the replication of DWV and SBV and

235 the expression of the AMPs controlled by the Toll pathway (defensin-1, GB41428), or the Imd 236 pathway (hymenoptaecin, GB51223), and the components of the melanisation pathway (putative 237 serpin, GB48820, and prophenoloxidase activating enzyme, GB50013), we quantified gene 238 expression levels in orally-infected larvae by qRT-PCR (Fig. 1A). While no increase of DWV 239 levels was observed at 4 dpi via the oral route compared to PBS controls, the SBV levels in the 240 virus-infected group were significantly higher than in the control, PBS-exposed insects (Fig. 241 3A). At 9 days post inoculation, the control insects exposed to the buffer (PBS) or to a UV242 inactivated preparation of DWV and SBV (UV-vir) showed similarly low levels of SBV and 243 DWV (Fig. 3B). These results demonstrate that our in vitro manipulations did not activate 244 replication of SBV and DWV that may already have been present at low levels in experimental 245 larvae or pupae.

As before, pupae that developed from larvae fed with infectious virus were stratified 247 according to the observed SBV and DWV levels at 9 dpi (Group "hSBV" - high SBV and low 248 DWV levels, Group "hDWV" - high DWV and low SBV levels, and Group "hSBV/hDWV" 249 high levels of both tested viruses) and the expression level of honeybee immune genes of interest 250 was quantified (Fig. 3). Both AMPs, hymenoptaecin and defensin-1, were up-regulated in Group 251 "hSBV" insects but remained at control levels in Group "hDWV" individuals (Fig. 3D, F). The 252 level of hymenoptaecin increased, but to a lower level in Group "hDWV/hSBV" than Group 253 "hSBV" (Fig. 3D) whereas expression of defensin-1 was similar in these groups (Fig. 3F). It is 254 possible that hymenoptaecin expression may be directly influenced by the level of SBV (which 
255 was lower in absolute terms in Group "hSBV/hDWV" than in Group "hSBV"). Alternatively, the

256 elevated levels of DWV in Group "hSBV/hDWV" may suppress Imd pathway activation -

257 which controls expression of hymenoptaecin - but not the Toll pathway-controlled defensin-1.

258 Group "hSBV" and "hSBV/hDWV" samples had elevated expression of the putative serpin and

259 reduced expression of PPAE compared to Group "hDWV" or controls fed PBS or UV-

260 inactivated virus preparation (Fig. 3H, 3J), implying that altered expression of these two

261 melanisation pathway genes could be a result of elevated SBV levels (Fig. 3B). The qRT-PCR

262 analyses were in good agreement with the RNA-Seq data (Table 3).

263

264

265

266

267

268

\section{Injection of honeybee pupae haemolymph with DWV and SBV}

High levels of orally-acquired SBV infection has a devastating effect on larval development (Bailey, Gibbs \& Woods, 1964). To investigate the influence of the route of virus acquisition on consequent gene expression we directly inoculated pupae by injection in vitro (Fig. 1B). We observed no pupae with high virus levels in the PBS-injected control group at 2 and 5 dpi, while high levels of DWV were observed in the DWV-injected pupae, and high levels of both SBV and DWV were present in all tested pupae injected with the SBV+DWV virus mixture (Fig. 4A, B). As we did not have access to pure SBV preparations due to the presence of DWV in all Warwickshire honeybee colonies (including the SBV-infected used for the virus preparations) and it was not possible to separate these viruses using biophysical methods, no injected pupae with high levels of SBV alone were produced and analyzed.

At 2 dpi there was no significant difference between expression levels of defensin-1 and serpin (Fig. 4E, G) whereas the expression of hymenoptaecin were significantly higher in the 
278 SBV+DWV-injected pupae compared to DWV-injected pupae (Fig. 4C). In contrast, PPAE

279 levels were higher in DWV-injected pupae than in those receiving both viruses (Fig. 4I). At 5

280 dpi, PPAE was significantly down-regulated in the SBV+DWV group, while the levels of PPAE

281 in the PBS and DWV groups were not significantly different (Fig. 4J). The same effects of high

282 levels of DWV and SBV on expression of PPAE were observed in the larval feeding experiment

283 (Fig. 3J). Expression levels of hymenoptaecin were significantly different between the pupae

284 injected with PBS, DWV, or SBV+DWV groups at 5 dpi, with the highest levels observed in the

285 SBV+DWV group and lowest in the control (PBS) group (Fig. 4D). In addition, at 5 dpi

286 defensin-1 and serpin (GB48820) were significantly up-regulated in the DWV pupae and

287 SBV+DWV-injected pupae compared to the PBS-injected control. There were no significant

288 differences between the pupae groups with high levels of DWV alone and high levels of both

289 SBV and DWV (Fig. 4F, H) at 5 dpi. Notably, high levels of DWV alone in the larval feeding

290 experiment did not alter the expression of defensin-1 and serpin (GB48820) (Fig. 3F, H, Group

291 "hDWV"). It is possible that high levels of DWV in the pupae infected by injection may

292 differentially affect the expression of defensin-1 and serpin (GB48820) compared to orally

293 infected larvae. Lourenco et al. (2013) have reported that adult bees exhibit elevated AMP levels

294 following injection. In the absence of bacterial challenge, wounding-associated AMP expression

295 levels decrease within 24 hours in bumblebees. Therefore, it is possible that high DWV levels

296 prevent the post-wounding resetting of defensin-1 levels.

297

298 Discussion

299 The Iflaviruses SBV and DWV cause distinctly different disease in A. mellifera with

300 symptoms characteristic to most beekeepers. To better understand the influence of the route of 
301 virus transmission on disease development we investigated changes in gene expression resulting

302 from orally administered or injected DWV and SBV. Transcriptome analysis of pupae showed

303 strong up-regulation of the expression of AMPs (defensin-1 and hymenoptaecin) in orally

304 infected larvae with high levels of SBV. Interestingly, high levels of DWV did not up-regulate

305 these AMPs in orally infected larvae (Fig. 3 D, F). In pupal injection experiments, whilst

306 defensin-1 was equally up-regulated in high DWV and high SBV+DWV groups compared to

307 controls (Fig 4 F), the hymenoptaecin expression showed significantly higher up-regulation in

308 the individual pupae with high levels of both viruses compared with those with high levels of

309 DWV alone (Fig. 4 D). This suggests that SBV was a more potent inducer of AMP expression

310 even in injected pupae, where injury alone may have an effect on activation of the signaling

311 pathways and up-regulation of AMPs in the honeybee larvae (Randolt et al., 2008) and young

312 adults (Lourenco et al., 2013).

313 Expression of AMPs in insects is regulated by the Toll and Imd signaling pathways and

314 induced by recognition of the bacterial or fungal pathogen-associated molecular patterns, such as

315 bacterial peptidoglycan (Lemaitre \& Hoffmann, 2007). Our results therefore raise interesting

316 questions including, (i) how replication of SBV, a single-stranded positive-sense RNA virus,

317 activates these signaling pathways and (ii) why DWV, a related Iflavirus with similar genome

318 composition, organization and replication, does not up-regulate AMPs when acquired orally.

319 Although up-regulation of expression of AMPs by RNA viruses has been reported previously

320 (including Drosophila C virus infection of Drosophila (Zhu, Ding \& Zhu, 2013) and dengue

321 virus infection of Aedes aegypti (Luplertlop et al., 2011)), it remains unclear how the Toll and

322 Imd signaling pathways are activated by these viruses as they normally respond to the 
323 peptigoglycans of Gram-positive and Gram-negative bacteria respectively (Lemaitre \&

324 Hoffmann, 2007).

325 Although the viral proteins encoded by SBV may directly and simultaneously

326 activate the Toll and Imd pathways (which will require further studies) an alternative

327 hypothesis is this results indirectly from SBV-induced pathogenesis. For example, the

328 extensive disruption of the tracheal epithelial lining and pertrophic membranes caused by SBV

329 infection (Mussen \& Furgala, 1977) may allow contamination of the haemolymph by bacteria

330 present in the tracheal or intestinal lining. This would result in recognition of the peptidoglycans

331 and consequent Toll and Imd pathway activation. In contrast, DWV infection does not lead to

332 disruption of the gut epithelium (Fievet et al., 2006) and even high levels of DWV,

333 commensurate with symptomatic infection, do not result in AMP up-regulation (Bull et al., 2012;

334 Nazzi et al., 2012; Ryabov et al., 2014). Further molecular studies will be required to

335 discriminate between the direct or indirect activation of Imd and Toll pathways following SBV

336 infection. It should be noted that a simplistic explanation of elevated bacterial levels in SBV-

337 infected pupae does not account for the observations. We quantified the total bacterial load by

338 qRT-PCR using generic primers for bacterial 16S rRNA (Table S1) (Nadkarni et al., 2002) and

339 observed no statistically significant differences between pupae with low and high levels of

340 DWV, SBV or the viruses combined within the same age and developmental stage groups (Fig.

341 S1). However, it is possible that the elevated AMP levels in SBV-infected pupae suppress

342 bacterial expansion so confounding simple quantification of bacterial levels.

343 Evolution has shaped the virulence and pathogenesis of viruses to facilitate their

344 transmission to new hosts. We speculate that the related Iflaviruses, SBV and DWV, induce

345 different responses in their host that suit their principal or evolutionarily-historical route of 
346 transmission. DWV, in the absence of the Varroa mite vectoring, is transmitted vertically via

347 queens and drone semen, and horizontally during trophylaxis (de Miranda \& Genersch, 2010;

348 Yue \& Genersch, 2005). DWV infection of the honeybee larvae does not halt development and

349 does not cause early death at the larval stage, which suggests that honeybee survival is essential

350 for DWV transmission and that this virus has evolved to minimize negative impact on the host.

351 (Fujiyuki et al., 2004; Ryabov et al., 2014). In marked contrast, horizontal oral transmission is

352 considered the principal route for SBV, which causes acute infections at the larval stage leading

353 to death before pupation, with the subsequent spread of SBV likely to involve cannibalization of

354 diseased larvae (Schmickl \& Crailsheim, 2001; Woyke, 1977). The observed suppression of the

355 melanisation pathway in the SBV-infected larvae, perhaps a consequence of the combined down-

356 regulation of PPAE and up-regulation of serpin (BeeBase accession number GB48820), may

357 favour SBV transmission as melanisation contributes to virus resistance and could decrease

358 infectivity of SBV particles in the larvae, thereby reducing horizontal transmission (Fig. 5). This

359 may be similar to the Semliki Forest Virus suppression of the phenoloxidase cascade in mosquito

360 (Rodriguez-Andres et al., 2012). In contrast, suppression of melanisation may be detrimental to

361 DWV transmission as it reduces honeybee survival and therefore reduces the opportunities for

362 vertical transmission of this virus (Fig. 5).

363 There is a possibility that up-regulation of AMP expression may prevent bacterial growth

364 and possible degradation of SBV particles in diseased larvae and pupae. Therefore this would

365 increase chances of SBV transmission when diseased larvae and pupae are removed and/or

366 cannibalized as part of the social immune response (Evans \& Spivak, 2010) (Fig. 5). Conversely,

367 activation of immune pathways, which result in up-regulation of AMP production is costly 
368 (Moret \& Schmid-Hempel, 2000) and therefore could negatively impact honeybee survival and

369 ultimately on DWV transmission (Fig. 5).

370

371 Conclusions

372 Our results indicate that evolutionarily-related Iflaviruses SBV and DWV, evoke

373 markedly different transcriptional responses in their honeybee host, including effects on the

374 expression of immune-related genes. We also observed dominance of the SBV-induced

375 transcriptome changes over the DWV-induced. Honeybee larvae with high levels of SBV

376 replication, showed concerted up-regulated expression of antimicrobial peptides (AMPs) and

377 down-regulated expression of the prophenoloxidase-activating enzyme (PPAE) together with up-

378 regulation of the expression of a putative serpin, which could lead to the suppression of the

379 melanisation pathway. The same effect was observed in the individuals with high levels of both

380 SBV and DWV, but high levels of DWV alone did not affect expression of the AMPs and the

381 genes involved in the regulation of melanisation. The effects of high SBV replication levels on

382 expression of these immune genes were unlikely to be the consequences SBV-induced

383 developmental changes, because some of them were observed in honeybees infected with SBV

384 by injection at the pupal stage. It is possible that different impacts of SBV and DWV on the

385 expression of immune-related genes may be an adaptation to horizontal and vertical transmission

386 routes, the principal transmission routes of SBV and DWV respectively. These findings provide

387 the basis for further studies of the contributions of AMPs and melanisation to virus-host

388 interactions and the transmission of insect viruses, including economically important species

389 such as honeybees. 
391

392

393

394

395

396

397

398

399

400

401

402

403

404

405

406

407

408

409

410

411

412

413

\section{Acknowledgements}

We thank Dr. Aronstein for the larval feeding technique.

\section{References}

Ai H, Yan X, Han R. 2012. Occurrence and prevalence of seven bee viruses in Apis mellifera and Apis cerana apiaries in China. Journal of Invertebrate Pathology 109:160-164 DOI:10.1016/j.jip.2011.10.006

Anders S, Huber W. 2010. Differential expression analysis for sequence count data. Genome Biology 11:R106 DOI 10.1186/gb-2010-11-10-r106.

Aronstein K, Saldivar E. 2005. Characterization of a honey bee Toll related receptor gene Am18w and its potential involvement in antimicrobial immune defense. Apidologie 36:3-14 DOI: 10.1051/apido:2004062.

\section{Ashburner M, Ball CA, Blake JA, Botstein D, Butler H, Cherry JM, Davis AP, Dolinski K,} Dwight SS, Eppig JT, Harris MA, Hill DP, Issel-Tarver L, Kasarskis A, Lewis S, Matese JC, Richardson JE, Ringwald M, Rubin GM, Sherlock G. 2000. Gene Ontology: tool for the unification of biology. Nature Genetics 25:25-29 DOI 10.1038/75556.

Bailey L. 1969. The multiplication and spread of Sacbrood virus of bees Apis mellifera. Annals of Applied Biology 63:483-491 DOI 10.1111/j.1744-7348.1969.tb02844.x.

Bailey L, Gibbs AJ, Woods RD. 1964. Sacbrood virus of the larval honey bee (Apis mellifera Linnaeus). Virology 23:425-429 DOI 10.1016/0042-6822(64)90266-1.

Blanchard P, Guillot S, Antunez K, Koeglberger H, Kryger P, de Miranda JR, Franco S, Chauzat M-P, Thiery R, Ribiere M. 2014. Development and validation of a real-time two-step RT-qPCR TaqMan (R) assay for quantitation of Sacbrood virus (SBV) and its application to a 
414 field survey of symptomatic honey bee colonies. Journal of Virological Methods 197:7-13 DOI 415 10.1016/j.jviromet.2013.09.012.

416 Bull JC, Ryabov EV, Prince G, Mead A., Zhang C, Baxter LA, Pell JK, Osborne JL,

417 Chandler D. 2012. A strong immune response in young adult honeybees masks their increased 418 susceptibility to infection compared to older bees. PLoS Pathogens 8:e1003083 DOI 419 doi:10.1371/journal.ppat.1003083.

420 Carbon S, Ireland A, Mungall CJ, Shu S, Marshall B, Lewis S, Ami GOH, Web Presence 421 Working Group. 2009. AmiGO: online access to ontology and annotation data. Bioinformatics 422 25: 288-289 DOI 10.1093/bioinformatics/btn615.

423 De Gregorio E, Spellman PT, Tzou P, Rubin GM, Lemaitre B. 2002. The Toll and Imd 424 pathways are the major regulators of the immune response in Drosophila. EMBO Journal 425 21:2568-2579 DOI 10.1093/emboj/21.11.2568.

de Miranda JR, Genersch E. 2010. Deformed wing virus. Journal of Invertebrate Pathology 427 103:S48-S61 DOI 10.1016/j.jip.2009.06.012.

Evans JD, Aronstein K, Chen YP, Hetru C., Imler JL, Jiang H, Kanost M, Thompson GJ, 429 Zou Z, Hultmark D. 2006. Immune pathways and defence mechanisms in honey bees Apis 430 mellifera. Insect Molecular Biology 15:645-656 DOI 10.1111/j.1365-2583.2006.00682.x.

Evans JD, Spivak M. 2010. Socialized medicine: Individual and communal disease barriers in 432 honey bees. Journal of Invertebrate Pathology 103:S62-S72 DOI 10.1016/j.jip.2009.06.019.

433 Fievet J, Tentcheva D, Gauthier L, de Miranda J, Cousserans F, Colin ME, Bergoin M. 434 2006. Localization of deformed wing virus infection in queen and drone Apis mellifera L. 435 Virology Journal 3:16 DOI 10.1186/1743-422X-3-16. 
436 Fujiyuki T, Takeuchi H, Ono M, Ohka S, Sasaki T, Nomoto A, Kubo T. 2004. Novel insect

437 picorna-like virus identified in the brains of aggressive worker honeybees. Journal of Virology

438 78:1093-1100 DOI 10.1128/JVI.78.3.1093-1100.2004.

439 Ghosh RC, Ball BV, Willcocks MM, Carter MJ. 1999. The nucleotide sequence of sacbrood 440 virus of the honey bee: an insect picorna-like virus. Journal of General Virology 80:1541-1549

441 DOI 10.1099/0022-1317-80-6-1541

442 Langmead B, Trapnell C, Pop M, Salzberg SL. 2009. Ultrafast and memory-efficient 443 alignment of short DNA sequences to the human genome. Genome Biology 10:R25 DOI $444 \quad 10.1186 / \mathrm{gb}-2009-10-3-r 25$.

445 Lanzi G, De Miranda JR, Boniotti MB, Cameron CE, Lavazza A, Capucci L, Camazine 446 SM, Rossi C. 2006. Molecular and biological characterization of deformed wing virus of 447 honeybees (Apis mellifera L.). Journal of Virology 80:4998-5009 DOI 10.1128/JVI.80.10.4998$448 \quad 5009.2006$.

449 Lemaitre B, Hoffmann J. 2007. The host defense of Drosophila melanogaster. Annual Review 450 of Immunology 25: 697-743 DOI 10.1146/annurev.immunol.25.022106.141615.

451 Lourenco AP, Guidugli-Lazzarini KR, Freitas FCP, Bitondi MMG, Simoes, ZLP. 2013.

452 Bacterial infection activates the immune system response and dysregulates microRNA 453 expression in honey bees. Insect Biochemistry and Molecular Biology 43:474e482 DOI $454 \quad 10.1016 /$ j.ibmb.2013.03.001

Luplertlop N, Surasombatpattana P, Patramool S, Dumas E, Wasinpiyamongkol L, Saune 456 L, Hamel R, Bernard E, Sereno D, Thomas F, Piquemal D, Yssel H, Briant L, Misse D. 457 2011. Induction of a peptide with activity against a broad spectrum of pathogens in the Aedes 
458 aegypti salivary gland, following Infection with Dengue virus. PLoS Pathogens 7:e1001252 DOI

45910.1371 journalppat.1001252.

460 Martin SJ, Highfield AC, Brettell L, Villalobos EM, Budge GE, Powell M, Nikaido S,

461 Schroeder DC. 2012. Global honey bee viral landscape altered by a parasitic mite. Science

462 336:1304-1306 DOI 10.1126/science.1220941.

463 McMenamin A, Genersch E. 2015. Honey bee (Apis mellifera) colony losses and associated

464 viruses. Current Opinion in Insect Sceince, 8:121-129 DOI 10.1016/j.cois.2015.01.015.

465 Moeckel N, Gisder S, Genersch E. 2011. Horizontal transmission of deformed wing virus:

466 pathological consequences in adult bees (Apis mellifera) depend on the transmission route.

467 Journal of General Virology 92:370-377 10.1099/vir.0.025940-0.

468 Moore J, Jironkin A, Chandler D, Burroughs N, Evans DJ. Ryabov EV. 2011.

469 Recombinants between Deformed wing virus and Varroa destructor virus-1 may prevail in

470 Varroa destructor-infested honeybee colonies. The Journal of General Virology 92:156-61 DOI

$471 \quad 10.1099 /$ vir.0.025965-0.

472 Moran NA, Hansen AK, Powell JE, Sabree ZL. 2012. Distinctive gut microbiota of honey 473 bees assessed using deep sampling from individual worker bees. Plos One 7:e36393 DOI 474 10.1371/journlal.pone.0036393.

475 Moret Y, Schmid-Hempel P. 2000. Survival for immunity: The price of immune system 476 activation for bumblebee workers. Science 290:1166-1168 DOI 10.1126/science.290.5494.1166.

477 Mussen EC, Furgala B. 1977. Replcation of Sacbrood virus in larval and adult honeybees, Apis 478 melifera. Journal of Invertebrate Pathology 30:20-34 DOI 10.1016/0022-2011(77)90033-7. 
479 Nadkarni MA, Martin FE, Jacques NA, Hunter N. 2002. Determination of bacterial load by 480 real-time PCR using a broad-range (universal) probe and primers set. Microbiology 148:257-266 481 DOI 10.1099/00221287-148-1-257

482 Nazzi F, Brown SP, Annoscia D, Del Piccolo F, Di Prisco G, Varricchio P, Della Vedova G, 483 Cattonaro F, Caprio E, Pennacchio F. 2012. Synergistic Parasite-Pathogen Interactions 484 Mediated by Host Immunity Can Drive the Collapse of Honeybee Colonies. PLoS Pathogens 485 8:e1002735 DOI 10.1371/journal.ppat.1002735.

Ongus JR, Peters D, Bonmatin JM, Bengsch E, Vlak JM, van Oers MM. 2004. Complete 487 sequence of a picorna-like virus of the genus Iflavirus replicating in the mite Varroa destructor. 488 Journal of General Virology 85:3747-3755 DOI 10.1099/vir.0.80470-0.

Robinson MD, McCarthy, D. J. and Smyth, G. K. (2010). edgeR: a Bioconductor package for 490 differential expression analysis of digital gene expression data. Bioinformatics 26:139-140 DOI 491 10.1093/bioinformatics/btp616.

Rodriguez-Andres J, Rani S, Varjak M, Chase-Topping ME, Beck MH, Ferguson MC, phenoloxidase activity acts as a mosquito innate immune response against infection with Semliki 495 forest virus. PLoS Pathogens 8:e1002977 DOI 10.1371/journal.ppat.1002977. mellifera) Prevails after Varroa destructor-Mediated, or In Vitro, Transmission. Plos Pathogens 10: e1004230 DOI 10.1371/journal.ppat.1004230. 
500 Schluns H, Crozier RH. 2007. Relish regulates expression of antimicrobial peptide genes in the

501 honeybee, Apis mellifera, shown by RNA interference. Insect Molecular Biology 16:753-759

502 DOI 10.1111/j.1365-2583.2007.00768.x.

503 Schmickl T, Crailsheim K. 2001. Cannibalism and early capping: strategy of honeybee colonies

504 in times of experimental pollen shortages. Journal of Comparative Physiology A 187:541-547

505 DOI 10.1007/s003590100226.

506 Simonet J, Gantzer C. 2006. Inactivation of poliovirus 1 and F-specific RNA phages and

507 degradation of their genomes by UV irradiation at 254 nanometers. Applied and Environmental 508 Microbiology 72:7671-7677 DOI 10.1128/AEM.01106-06.

509 Soderhall K, Cerenius L. 1998. Role of the prophenoloxidase-activating system in invertebrate 510 immunity. Current Opinion in Immunology 10:23-28 DOI 0.1016/S0952-7915(98)80026-5.

511 Tukey J. 1949. Comparing individual means in the analysis of variance. Biometrics 5: 99-114.

512 Vanbergen AJ, Baude M, Biesmeijer JC, Britton NF, Brown MJF, Brown M, Bryden J,

513 Budge GE, Bull JC, Carvel C, Challinor AJ, Connolly CN, Evans DJ, Feil EJ, Garratt MP,

514 Greco MK, Heard MS, Jansen VAA, Keeling MJ, Kunis WE, Marris GC, Memmott J, 515 Murray JT, Nicolson SW, Osborne JL, Paxton RJ, Pirk CWW, Polce C, Potts SG, Priest 516 NK, Raine NE, Roberts S, Ryabov EV, Shafir S, Shirley MDF, Simpson SJ, Stevenson PC,

517 Stone GN, Termansen M, Wright GA. 2013. Threats to an ecosystem service: pressures on 518 pollinators. Frontiers in Ecology and the Environment 11:251-259 DOI 10.1890/120126.

519 Randolt K, Gimple O, Geissendörfer J, Reinders J, Prusko C. Mueller MJ, Albert S, Tautz

520 J, Beier H. 2008. Immune-related proteins induced in the hemolymph after aseptic and septic 
521 injury differ in honey bee worker larvae and adults. Archives of Insect Biochemistry and

522 Physiology 69:155e167.

523 Vandenberg JD, Shimanuki H. 1987. Techniques for rearing worker honeybees in the

524 laboratory. Journal of Apicultural Research 26:90-97 DOI 10.1080/00218839.1987.11100743.

525 Woyke J. 1977. Cannibalism and brood-rearing efficiency in the honeybee. Journal of 526 Apicultural Research 16:84-94 DOI 10.1080/00218839.1977.11099866.

527 Yue C, Genersch E. 2005. RT-PCR analysis of Deformed wing virus in honeybees (Apis 528 mellifera) and mites (Varroa destructor). Journal of General Virology 86:3419-3424 DOI 529 10.1099/vir.0.81401-0.

530 Zhu F, Ding H, Zhu B. (2013). Transcriptional profiling of Drosophila S2 cells in early 531 response to Drosophila C virus. Virology Journal 10:210 DOI 10.1186/1743-422X-10-210 


\section{Table 1 (on next page)}

Table 1

Summary of the NGS libraries of the larval oral inoculation experiment. 
Table 1. Summary of the NGS libraries of the larval oral inoculation experiment.

\begin{tabular}{|c|c|c|c|c|c|c|c|c|}
\hline $\begin{array}{c}\text { Sample } \\
\text { ID }\end{array}$ & $\begin{array}{l}\text { Treatment } \\
\text { group }\end{array}$ & $\begin{array}{c}\text { ENA sample } \\
\text { accession }\end{array}$ & Total reads & $\begin{array}{l}\text { A. mellifera } \\
\text { OGS3, } \\
\text { mRNA reads }\end{array}$ & $\begin{array}{c}\text { Total DWV } \\
\text { reads } \\
\text { (Aligned to } \\
\text { GenBank } \\
\text { accession } \\
\text { number } \\
\text { NC_004830) }\end{array}$ & $\begin{array}{l}\text { DWV to actin } \\
\text { mRNA } \\
\text { (GB44311) } \\
\text { coverage } \\
\text { ratio }\end{array}$ & $\begin{array}{c}\text { Total SBV } \\
\text { reads } \\
\text { (Aligned to } \\
\text { GenBank } \\
\text { accession } \\
\text { number } \\
\text { AF092924) }\end{array}$ & $\begin{array}{c}\text { SBV to actin } \\
\text { mRNA } \\
\text { (GB44311) } \\
\text { coverage } \\
\text { ratio }\end{array}$ \\
\hline 1 & Control & SAMEA2591288 & 9691343 & 6842703 & 7555 & 0.047 & 28541 & 0.201 \\
\hline 2 & Control & SAMEA2591289 & 10630145 & 6204592 & 6210 & 0.049 & 4009 & 0.036 \\
\hline 3 & DWV & SAMEA2591290 & 9785423 & 3352681 & 3240468 & 55.263 & 6179 & 0.120 \\
\hline 4 & $\mathrm{SBV}+\mathrm{DWV}$ & SAMEA2591291 & 10069125 & 645114 & 736640 & 34.841 & 7021099 & 378.684 \\
\hline 5 & $\mathrm{SBV}+\mathrm{DWV}$ & SAMEA2591292 & 10257560 & 604367 & 887349 & 54.627 & 8171254 & 573.641 \\
\hline
\end{tabular}




\section{Table 2 (on next page)}

Table 2

Gene ontology (GO) Biological Process (BP) terms associated with the up-regulated and down-regulated differentially expressed genes in the honeybees of the larval feeding NGS experiments (only the top 10 over-represented GO PB terms with the lowest $p$-values are shown). 
Table 2. Gene ontology (GO) Biological Process (BP) terms associated with the upregulated and downregulated differentially expressed genes in the honeybees of the larval feeding NGS experiments (only the top 10 overrepresented GO PB terms with the lowest p-values are shown).

\section{Contrast 3}

Upregulated DE genes

\begin{tabular}{lccc} 
GO Term & P-value & $\begin{array}{l}\text { Sample } \\
\text { frequency }\end{array}$ & Background frequency \\
\hline GO:0006412 translation & $3.31 \mathrm{E}-05$ & $31 / 186(16.7 \%)$ & $787 / 14580(5.4 \%)$ \\
GO:0044237 cellular metabolic process & $1.87 \mathrm{E}-04$ & $96 / 186(51.6 \%)$ & $4811 / 14580(33.0 \%)$ \\
GO:0009161 ribonucleoside monophosphate metabolic process & $2.16 \mathrm{E}-04$ & $12 / 186(6.5 \%)$ & $132 / 14580(0.9 \%)$ \\
GO:0009123 nucleoside monophosphate metabolic process & $2.35 \mathrm{E}-04$ & $12 / 186(6.5 \%)$ & $133 / 14580(0.9 \%)$ \\
GO:0046034 ATP metabolic process & $3.67 \mathrm{E}-04$ & $11 / 186(5.9 \%)$ & $113 / 14580(0.8 \%)$ \\
GO:0032543 mitochondrial translation & $6.05 \mathrm{E}-04$ & $6 / 186(3.2 \%)$ & $23 / 14580(0.2 \%)$ \\
GO:0009167 purine ribonucleoside monophosphate metabolic & $1.11 \mathrm{E}-03$ & $11 / 186(5.9 \%)$ & $126 / 14580(0.9 \%)$ \\
process & & & $126 / 14580(0.9 \%)$ \\
GO:0009126 purine nucleoside monophosphate metabolic & $1.11 \mathrm{E}-03$ & $11 / 186(5.9 \%)$ & \\
process & & & \\
GO:0010467 gene expression & $4.08 \mathrm{E}-03$ & $56 / 186(30.1 \%)$ & $2397 / 14580(16.4 \%)$ \\
GO:0044249 cellular biosynthetic process & $5.38 \mathrm{E}-03$ & $56 / 186(30.1 \%)$ & $2418 / 14580(16.6 \%)$ \\
\hline
\end{tabular}

\section{Contrast 3}

Downregulated DE genes

none

Commonality between Contrasts 2, 4, and 5

Upregulated DE genes

\begin{tabular}{lccl}
\hline GO Term & P-value & $\begin{array}{l}\text { Sample } \\
\text { frequency }\end{array}$ & Background frequency \\
\hline GO:0050896 response to stimulus & $1.11 \mathrm{E}-10$ & $104 / 263(39.5 \%)$ & $2855 / 14580(19.6 \%)$ \\
GO:0006950 response to stress & $3.34 \mathrm{E}-10$ & $57 / 263(21.7 \%)$ & $1084 / 14580(7.4 \%)$
\end{tabular}


GO:0002376 immune system process GO:0006952 defense response

$1.04 \mathrm{E}-0$

$33 / 263(12.5 \%)$

$405 / 14580(2.8 \%)$

GO:0044699 single-organism process

9.74E-08

$29 / 263(11.0 \%)$

$373 / 14580(2.6 \%)$

GO:0006955 immune response

$6.35 \mathrm{E}-07$

$194 / 263(73.8 \%)$

$8031 / 14580(55.1 \%)$

GO:0065007 biological regulation

2.61E-06

5.27E-06

GO:0044763 single-organism cellular process

$24 / 263(9.1 \%)$

$298 / 14580(2.0 \%)$

GO:0045087 innate immune response

$7.96 \mathrm{E}-06$

$109 / 263(41.4 \%)$

$3621 / 14580(24.8 \%)$

$6.92 \mathrm{E}-05$

$154 / 263(58.6 \%)$

$5930 / 14580(40.7 \%)$

GO:0044707 single-multicellular organism process

$2.72 \mathrm{E}-04 \quad 115 / 263(43.7 \%) \quad 4170 / 14580(28.6 \%)$

Commonality between Contrasts 2, 4, and 5

Downregulated DE genes

\begin{tabular}{lccc}
\hline GO Term & P-value & $\begin{array}{l}\text { Sample } \\
\text { frequency }\end{array}$ & Background frequency \\
\hline GO:0042335 cuticle development & $3.78 \mathrm{E}-12$ & $27 / 242(11.2 \%)$ & $234 / 14580(1.6 \%)$ \\
GO:0040003 chitin-based cuticle development & $7.15 \mathrm{E}-11$ & $23 / 242(9.5 \%)$ & $182 / 14580(1.2 \%)$ \\
GO:0030239 myofibril assembly & $8.95 \mathrm{E}-10$ & $12 / 242(5.0 \%)$ & $37 / 14580(0.3 \%)$ \\
GO:0055002 striated muscle cell development & $6.24 \mathrm{E}-08$ & $12 / 242(5.0 \%)$ & $51 / 14580(0.3 \%)$ \\
GO:0055001 muscle cell development & $6.24 \mathrm{E}-08$ & $12 / 242(5.0 \%)$ & $51 / 14580(0.3 \%)$ \\
GO:0031032 actomyosin structure organization & $2.26 \mathrm{E}-07$ & $13 / 242(5.4 \%)$ & $70 / 14580(0.5 \%)$ \\
GO:0006030 chitin metabolic process & $3.65 \mathrm{E}-07$ & $16 / 242(6.6 \%)$ & $122 / 14580(0.8 \%)$ \\
GO:1901071 glucosamine-containing compound metabolic & $1.07 \mathrm{E}-06$ & $16 / 242(6.6 \%)$ & $131 / 14580(0.9 \%)$ \\
process & & & \\
GO:0006040 amino sugar metabolic process & $1.21 \mathrm{E}-06$ & $16 / 242(6.6 \%)$ & $132 / 14580(0.9 \%)$ \\
GO:0006022 aminoglycan metabolic process & $5.98 \mathrm{E}-06$ & $16 / 242(6.6 \%)$ & $147 / 14580(1.0 \%)$ \\
\hline
\end{tabular}

1 


\section{Table 3(on next page)}

Table 3

Differential expression (DE) of the putative honeybee antimicrobial peptides (AMPs), melanisation, Toll, and Imd pathway genes in the larval feeding experiment. Fold change values ( $\log _{2}$ transformed) are shown only for the genes DE in the contrast. Expression of the genes marked with * was quantified by qRT-PCR. DE genes were identified by both DESeq and edgeR analyses, with adjusted $p<0.05$ and false discovery rate, $F D R<0.05$ respectively. 
Table 3. Differential expression (DE) of the putative honeybee antimicrobial peptides (AMPs), melanisation, Toll, and Imd pathway genes in the larval feeding experiment. Fold change values $\left(\log _{2}\right.$ transformed) are shown only for the genes DE in the contrast. Expression of the genes marked with * was quantified by qRT-PCR. DE genes were identified by both DESeq and edgeR analyses, with adjusted $p<0.05$ and false discovery rate, FDR $<0.05$ respectively.

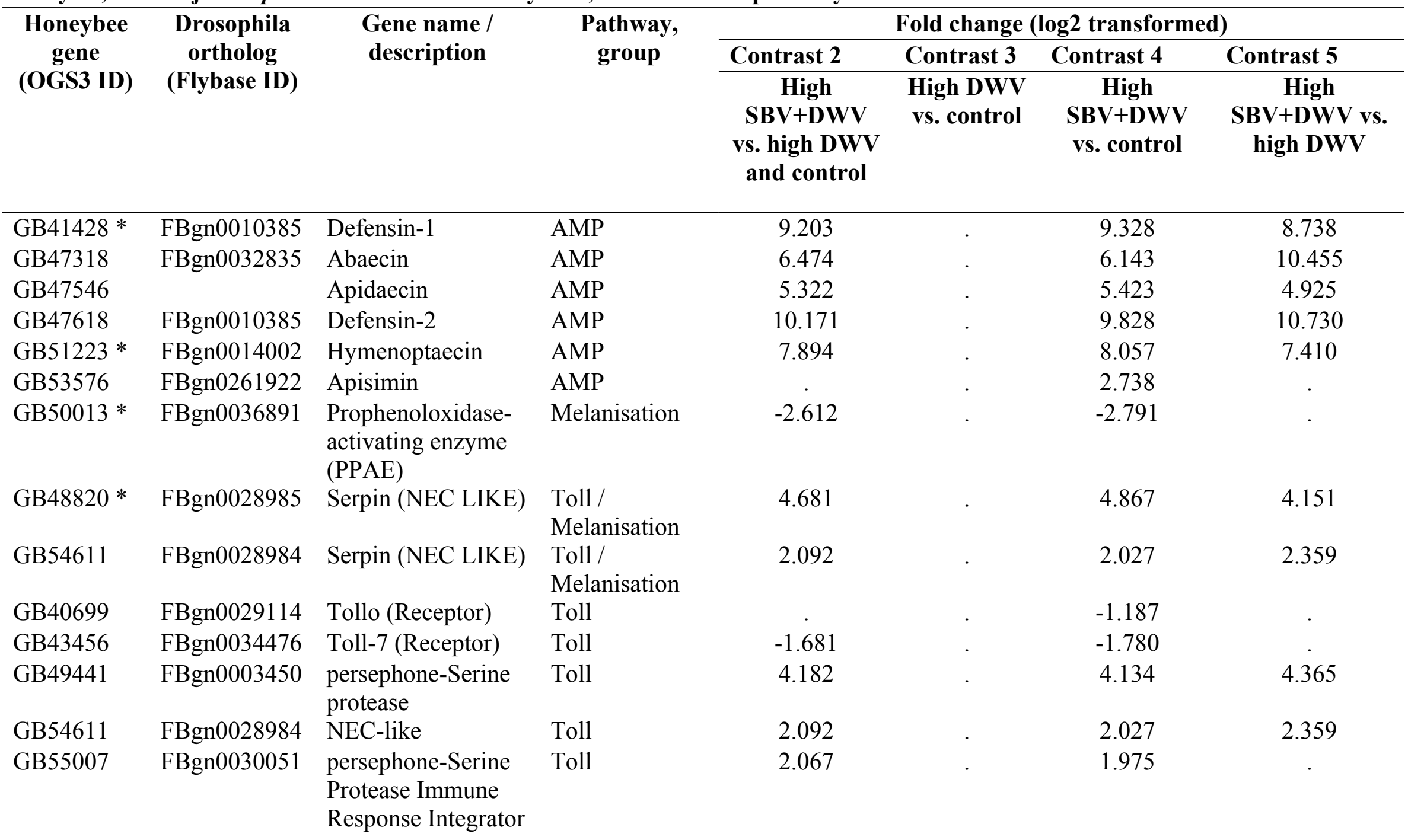




\begin{tabular}{|c|c|c|c|c|c|c|c|}
\hline GB44055 & FBgn0000250 & $\begin{array}{l}\text { cactus (NF-kappa-B } \\
\text { inhibitor) }\end{array}$ & Toll & & & 2.372 & 2.457 \\
\hline GB50418 & FBgn0262473 & Toll-1 (Receptor) & Toll & 2.073 & . & 2.104 & 1.962 \\
\hline GB51741 & FBgn0030310 & $\begin{array}{l}\text { Peptidoglycan } \\
\text { recognition protein } \\
\text { SA }\end{array}$ & Toll & 2.070 & . & 2.056 & 2.119 \\
\hline GB52631 & FBgn0003495 & spatzle & Toll & 3.224 & & 3.284 & 3.012 \\
\hline GB51498 & FBgn0033402 & Myd88 & Toll & & 1.549 & nd & . \\
\hline GB48707 & FBgn0024222 & $\begin{array}{l}\text { immune response } \\
\text { deficient } 5\end{array}$ & Toll & & 1.340 & nd & . \\
\hline GB42500 & FBgn0035976 & PGRP-LC & Imd & 1.515 & & 1.462 & 1.723 \\
\hline GB45648 & FBgn0013983 & imd & Imd & & & 1.240 & . \\
\hline
\end{tabular}




\section{1}

Figure 1

Schematic representation of experimental infection of honeybees with SBV and DWV, (A) larval oral inoculation, and (B) pupal haemolymph injection.

\section{A. Oral inoculation of honeybee larvae}

- Control (PBS)

- UV-inactivated virus (SBV+DWV)

- Virus (SBV+DWV)

Larvae (day 3)

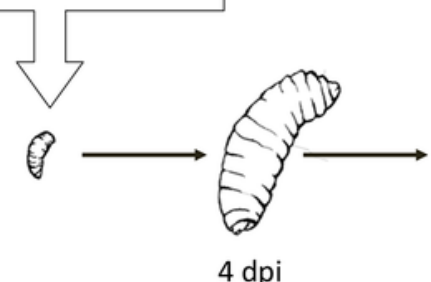

$4 \mathrm{dpi}$

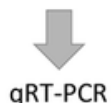

qRT-PCR

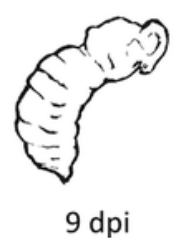

qRT-PCR RNA-Seq
B. Haemolymph injection of honeybee pupae

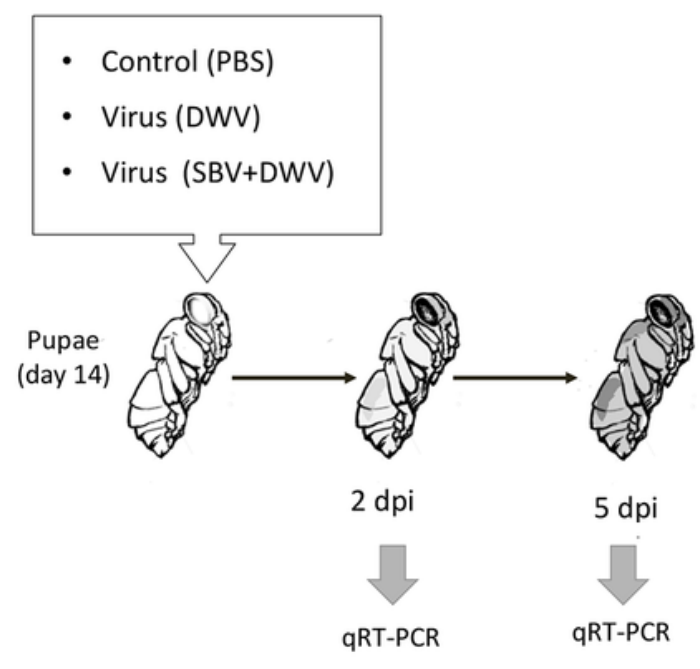


2

Figure 2

Effect of virus infection on global honeybee gene expression, RNA-Seq experiment:

experimental groups and contrasts. Arrows indicate direction of the contrasts (head against tail). The numbers of differentially expressed (DE) honeybee genes and of DE immunerelated genes are shown for each of the contrasts. 

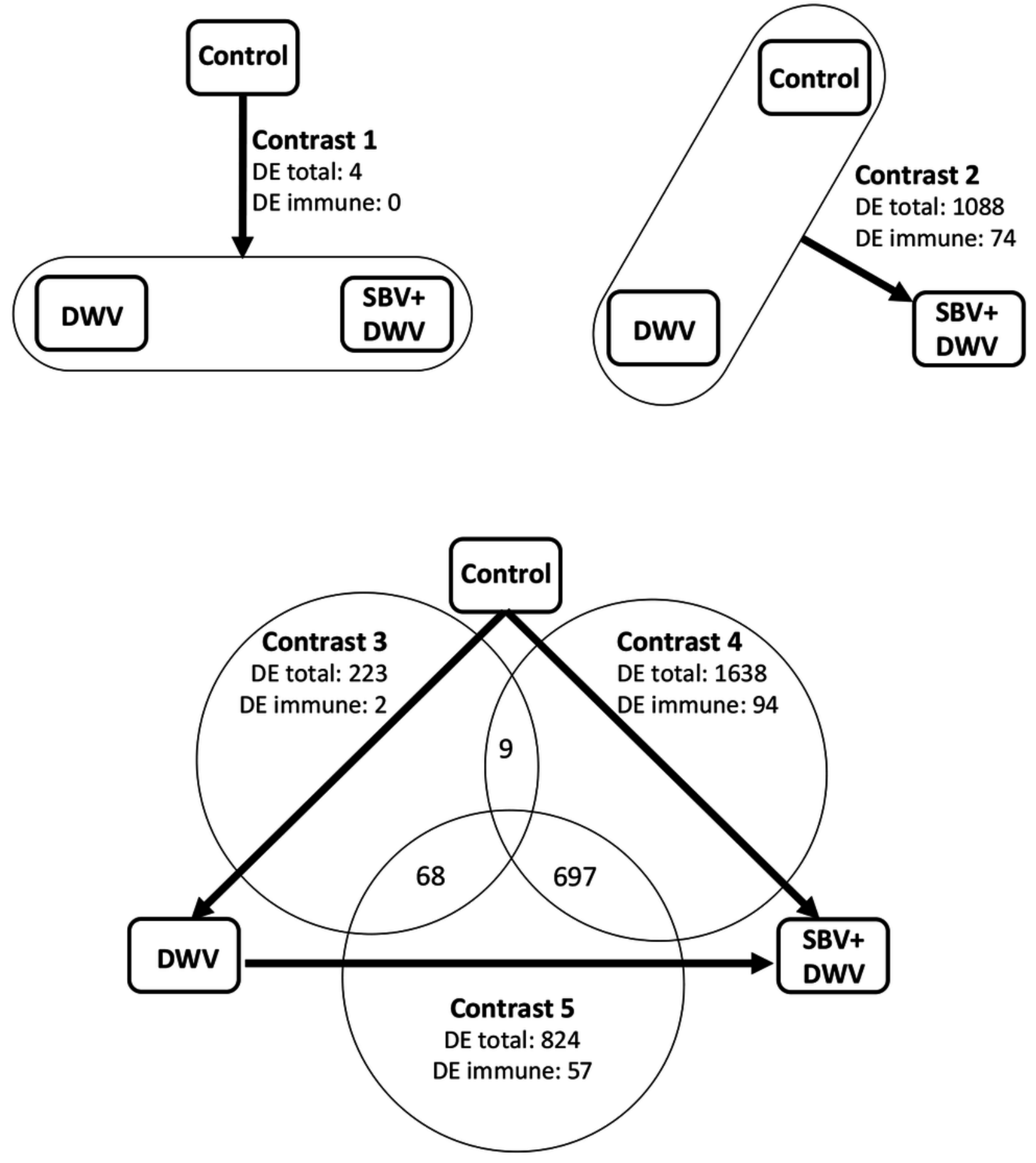


\section{3}

Figure 3

Oral infection. The relative levels of SBV and DWV genomic RNAs (A, B), and the AMPs: Imd pathway-controlled hymenoptaecin, GB51223 (C, D) and Toll pathway-controlled defensin-1, GB41428 (E, F), putative serpin, $G B 48820(G, H)$, and prophenoloxidase activating enzyme, PPAE, GB50013 (I, J). The number of analyzed larvae for the treatment groups were as follows: for the 4 days post inoculation (d.p.i.) groups $n=6$, for the 9 d.p.i groups $n=12$. Transcripts were quantified by qRT-PCR. Bars show mean $\triangle \mathrm{Ct}$ values, which were calculated by subtracting Ct values for Rp49 (GB47740) from the Ct values of the target genes, and standard deviation (SD). Bars significantly different at $p<0.01$ (using Tukey's HSD) are indicated using different letters. NS denotes "not significant". 
Larval oral inoculation
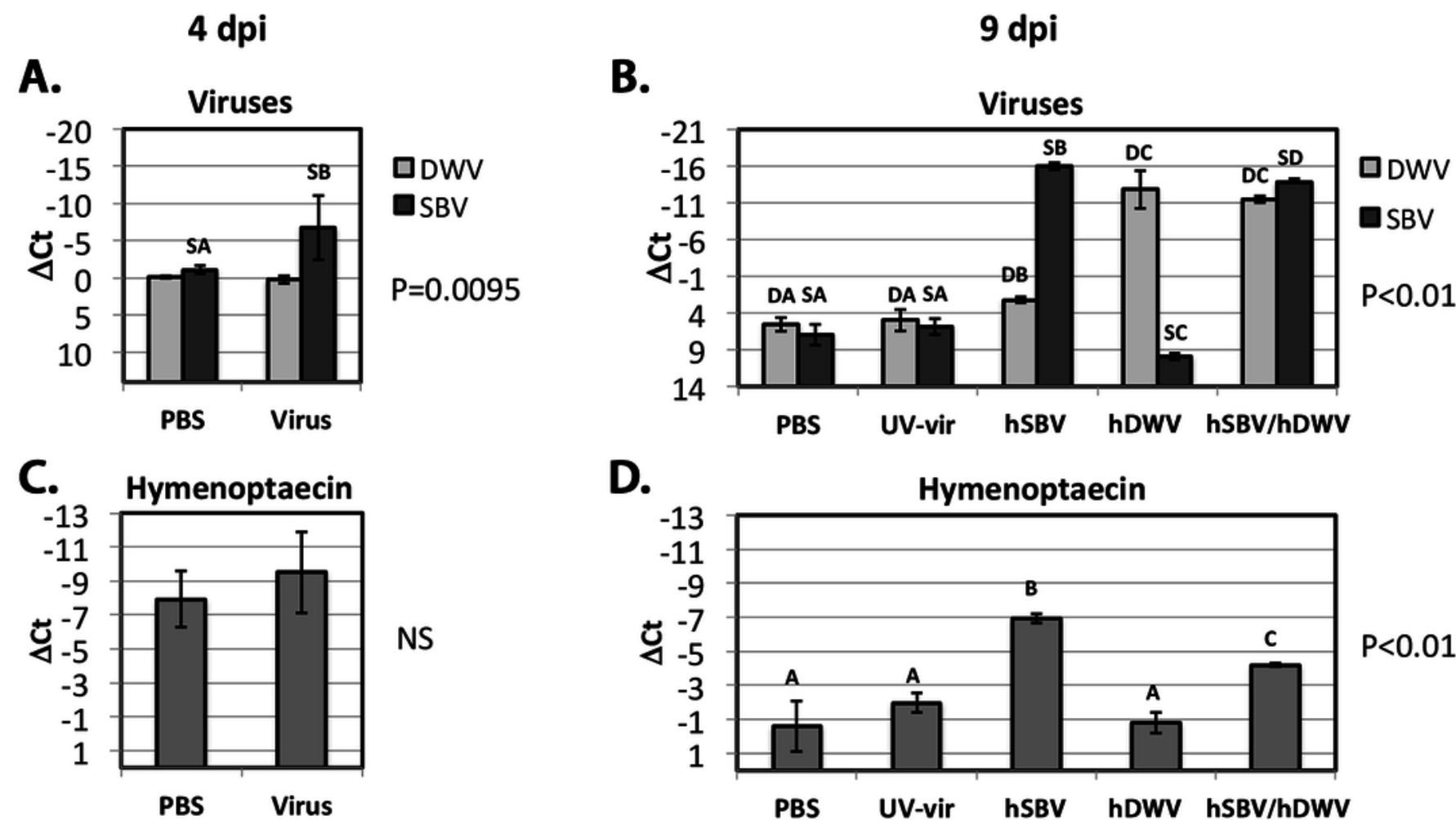

D.
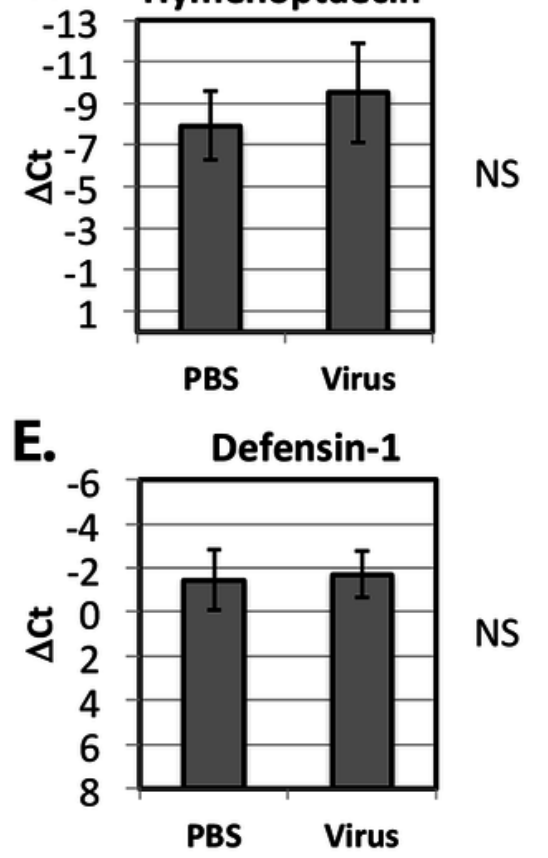

F.
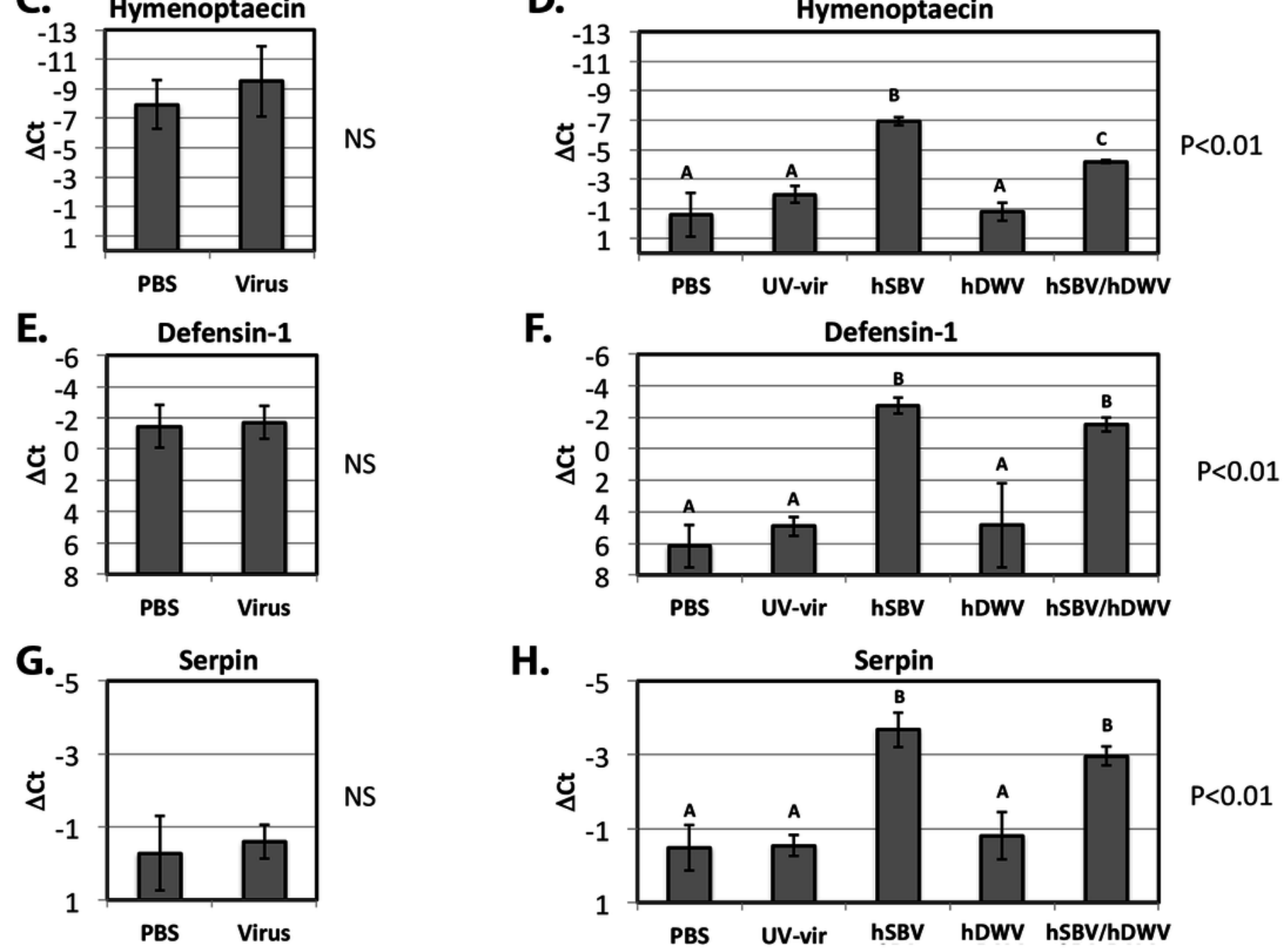

H.
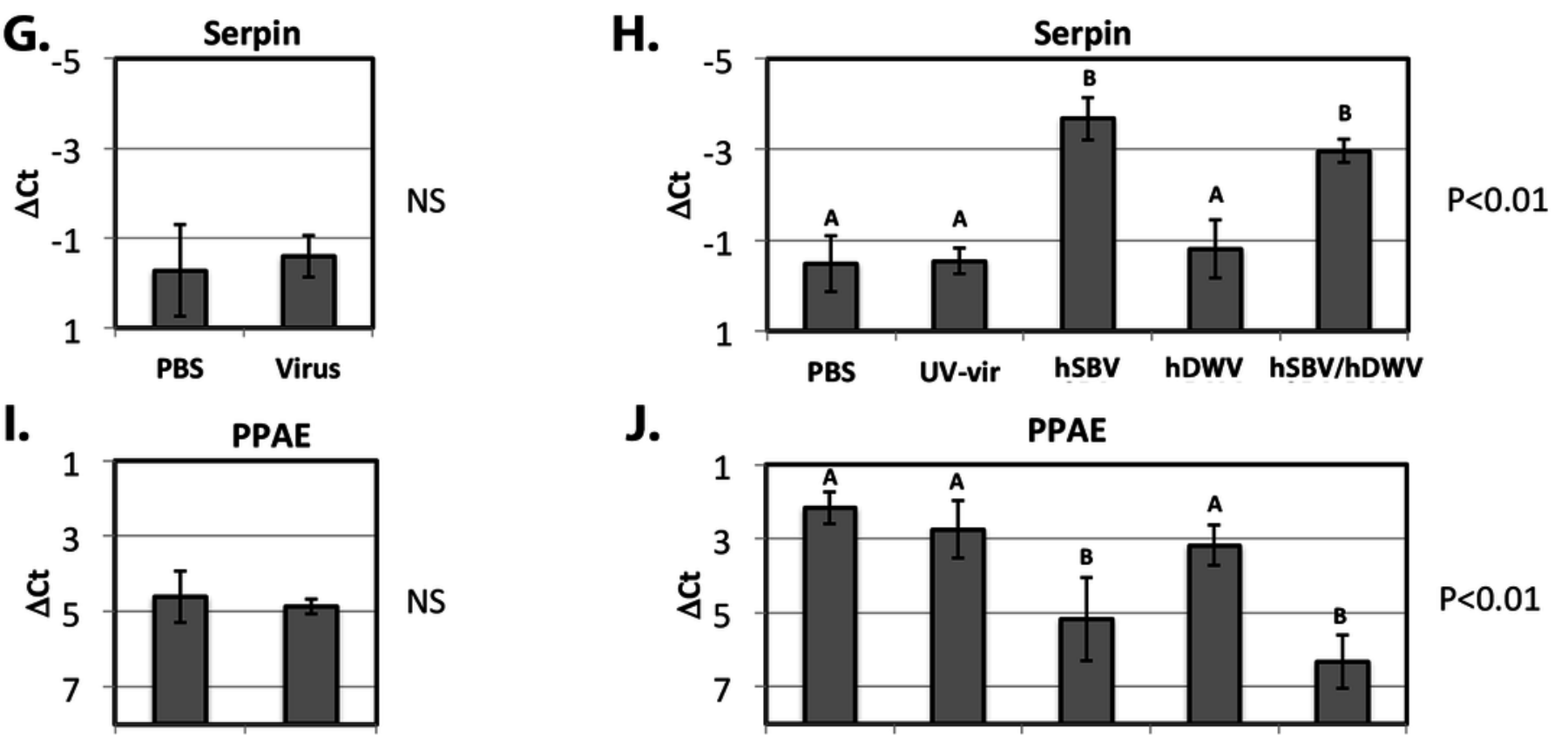

J.

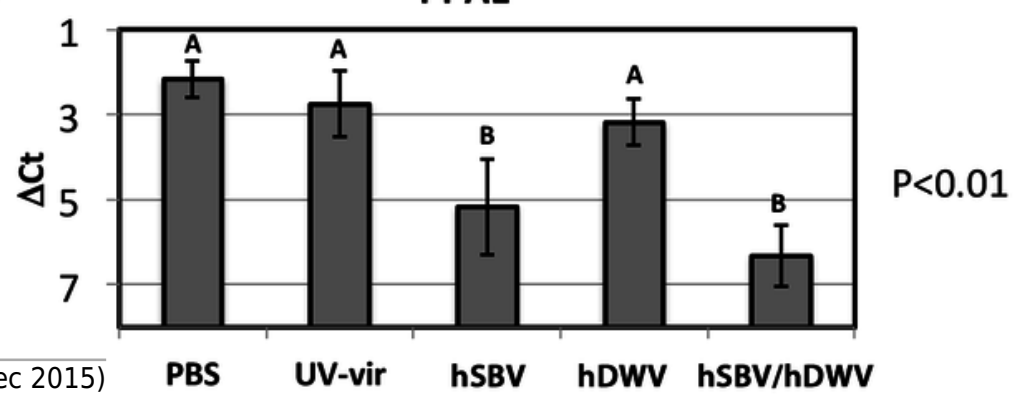




\section{4}

Figure 4

Pupal injection. The relative levels of SBV and DWV genomic RNAs (A, B), and the AMPs: Imd pathway-controlled hymenoptaecin, GB51223 (C, D) and Toll pathway-controlled defensin-1, GB41428 (E, F), putative serpin, $G B 48820(G, H)$, and prophenoloxidase activating enzyme, PPAE, GB50013 (I, J). The numbers of analyzed pupae for the treatment groups were as follows: for the 2 days post inoculation (d.p.i.) groups $n=6$, for the 9 d.p.i groups $n=12$. Transcripts were quantified by qRT-PCR. Bars show mean $\Delta$ Ct values, which were calculated by subtracting Ct values for Rp49 (GB47740) from the Ct values of the target genes, and standard deviation (SD). Bars significantly different at $p<0.01$ (using Tukey's HSD) are indicated using different letters. NS denotes "not significant". 
A.

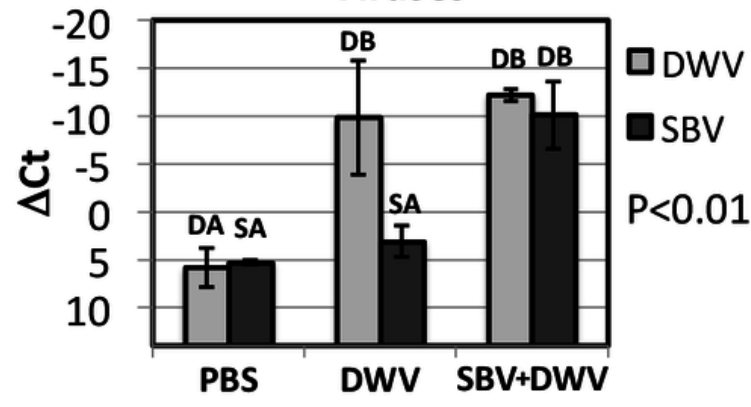

C.

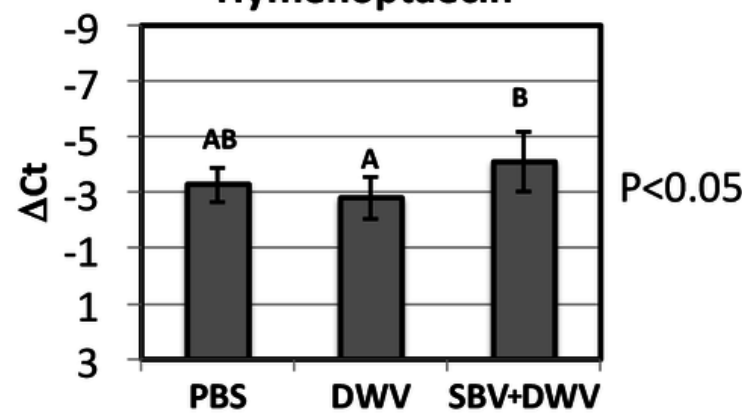

E.

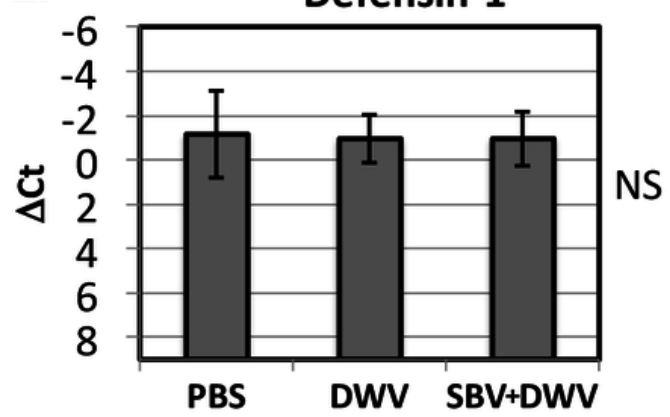

G.

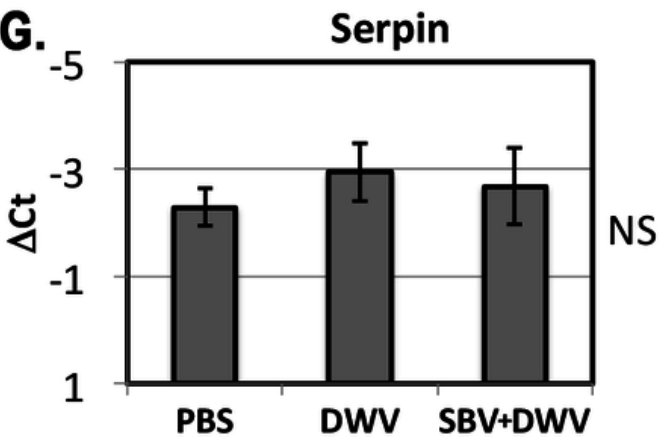

I.

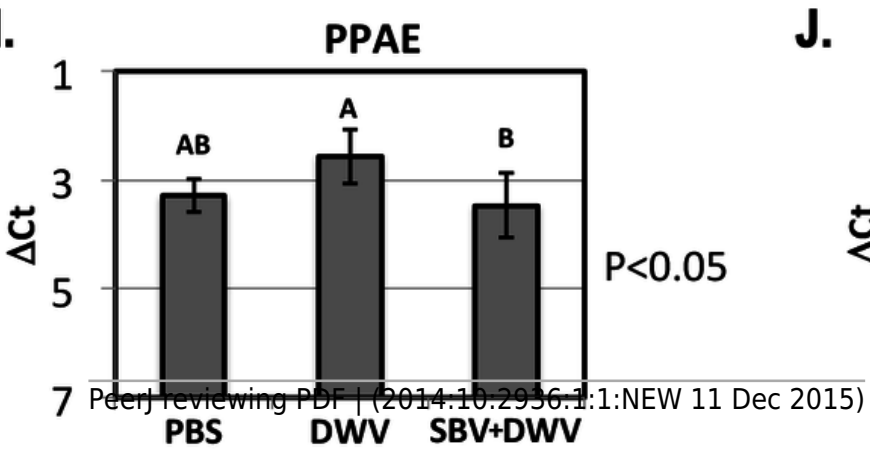

B.

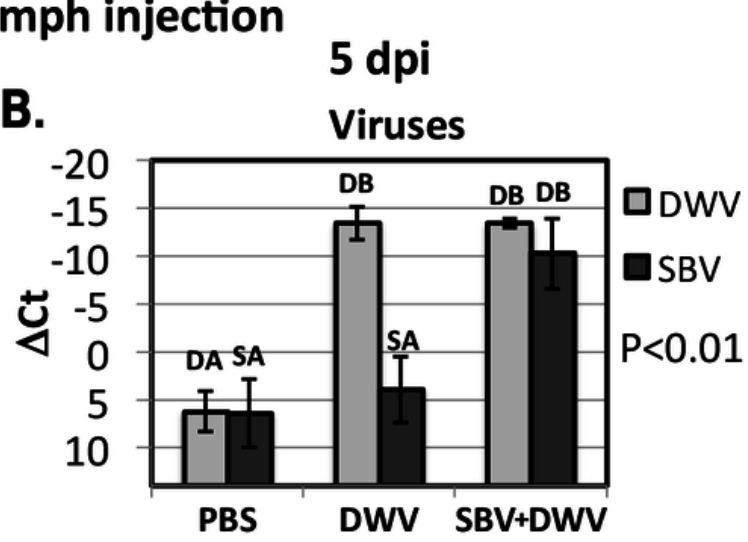

D.

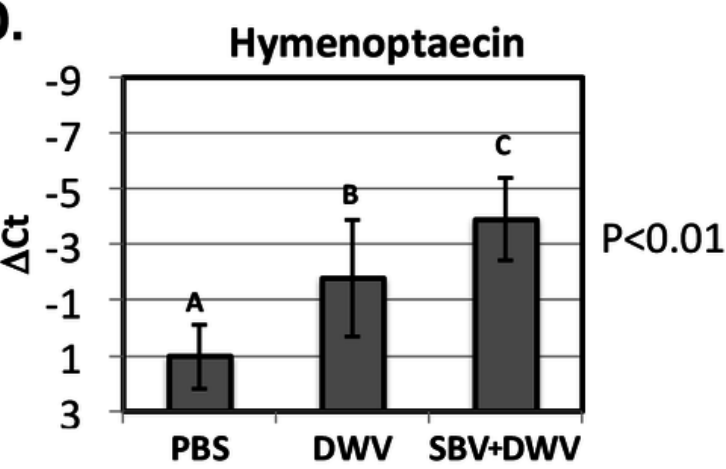

F.
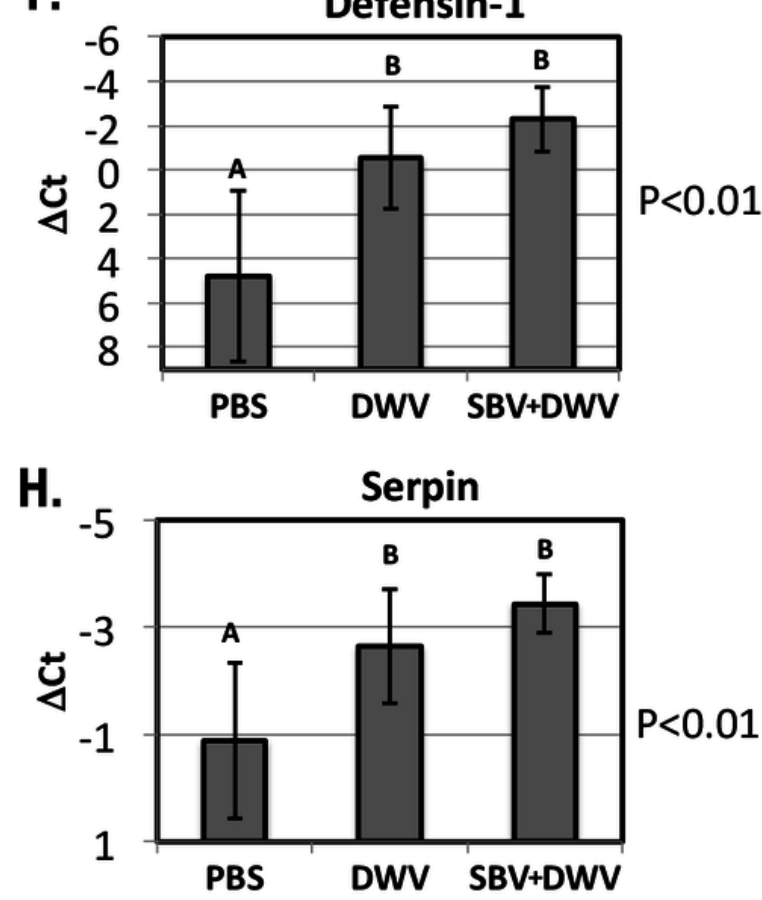

J.

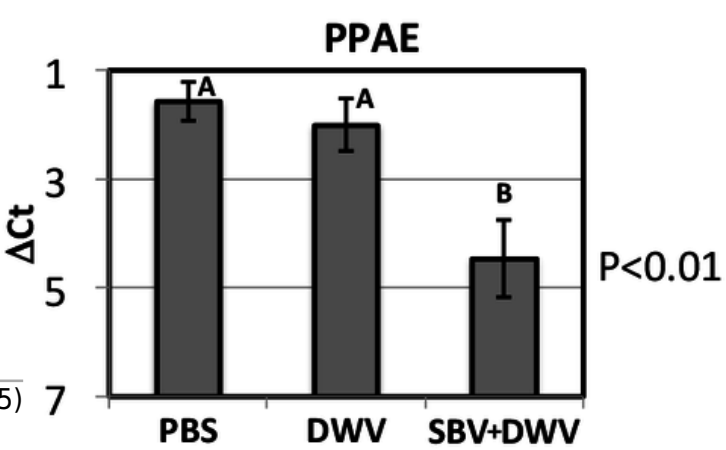


Figure 5

Schematic representation of the impacts of SBV and DWV infections on the melanisation pathway, AMP production, host survival and viral transmission.

\section{DWV (Varroa-free)}

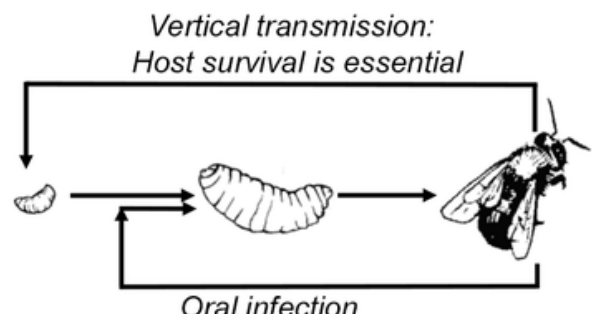

Oral infection

Live adults as a source of DWV infection

\section{Upregulation of antimicrobial peptides}

Cost to produce AMPs negative impact on the longterm host fitness and DWV survival and transmission

Effect on the host fitness is irrelevant, death at larval stage

Reduced bacterial growth in the dead insects - improved horizontal transmission of SBV

\section{Suppression of melanization}

Reduced ability to withstand other infections, reduced long-term survival of the host -

negative impact on the host and on DWV survival and transmission

\section{SBV}

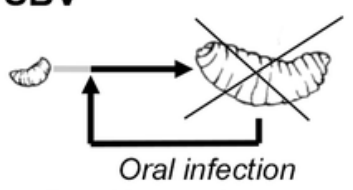

Dead larvae / pupae as

a source of SBV infection
Higher susceptibility to SBV in insects with suppressed melanization, effect on the host fitness is irrelevant, death at larval stage

Reduced loss of SBV infectivity due to melanization - positive impact on SBV horizontal transmission 